\title{
Distal blind-ending branch of a bifid ureter
}

Osman Raif Karabacak ${ }^{1}$, Halil Bozkurt ${ }^{1}$, Alper Dilli², Fatih Yalcinkaya ${ }^{1}$, Nurettin Sertcelik ${ }^{1}$

\begin{abstract}
Department of Urology, Diskapi Yildirim Beyazit Training and Research Hospital, Ministry of Health, Irfan Bastug Caddesi, Diskapi, Ankara, Turkey 2Department of Radiology, Ministry of Health, Diskapi Yildirim Beyazit Training and Research Hospital, Ankara, Turkey
\end{abstract}

Submitted: 26 June 2011

Accepted: 25 September 2011

Arch Med Sci 2013; 9, 1: 188-190

DOI: 10.5114/aoms.2012.30951

Copyright $\odot 2013$ Termedia \& Banach

Ureteral duplication is a common congenital anomaly of the urinary system observed in $0.8 \%$ of autopsy series [1]. However, bifid ureter with a blind branch is a rare condition. It is three times more prevalent in women than men and is observed twice as often on the right side as on the left side [2]. It does not generally give any clinical symptoms. However, in the literature, symptomatic cases with haematuria, flank pain, urinary infection, stone, vesicoureteral reflux and abdominal mass have been reported $[3,4]$.

We report a case on which ureteroscopy was performed to the right ureteral duplication with a blind-ending branch and left distal-end ureteral stone.

A 40-year-old woman was admitted to our clinic with acute left renal colic, dysuria and frequency micturition. She had no previous history of urinary tract symptoms. Laboratory tests showed normal renal function. Urine analysis and culture showed haematuria without infection.

In the direct urinary system graphy (DUSG) and ultrasonography (US) a left distal ureteral stone was detected; hence excretory urography (EU) was also performed on the patient. The EU showed a distal ureteral stone on the left side and two radio-opaque shadows in the region of the distal right ureter (Figures 1, 2). Surgery for the ureter stone and diagnostic ureteroscopy (DU) on the ureter with anomaly were planned to be performed in the same session. Ureteroscopic stone removal was performed on the left sided distal ureteral stone. In same session, DU was performed and distal blind-ending branch of bifid ureter $7 \mathrm{~cm}$ long was confirmed at the position $5 \mathrm{~cm}$ from the beginning of the ureterovesical junction (Figure 3).

No pathology was determined in the lumen of the blind-ending branch. The images were recorded on DU. The patient was discharged from the hospital the day following the operation. Since no complication related to ureter anomaly developed in the post-operative follow-up, blind-ending ureter was not intervened.

Blind-ending bifid ureter is a rare congenital anomaly of the ureter which has three sub-types according to the localization. These are proximal, distal, and middle according to their frequencies [2]. Our case was a distal blind-ending ureter, which is less frequent than the proximal and more frequent than the middle blind-ending bifid ureter.

Many blind-ending ureters are clinically insignificant and do not give any symptoms because of this. Patients who develop symptoms generally have complaints about abdominal pain, dysuria, frequency micturition, and haematuria. These complaints might depend on stone formation, vesi-
Corresponding author: Dr. Alper Dilli

Department of Radiology Dıskapı Yildirim Beyazit Training and Research Hospital Ministry of Health 06110 Dıskapı/Ankara Turkey

Phone: +905304653941

E-mail: alperdilli@yahoo.com 


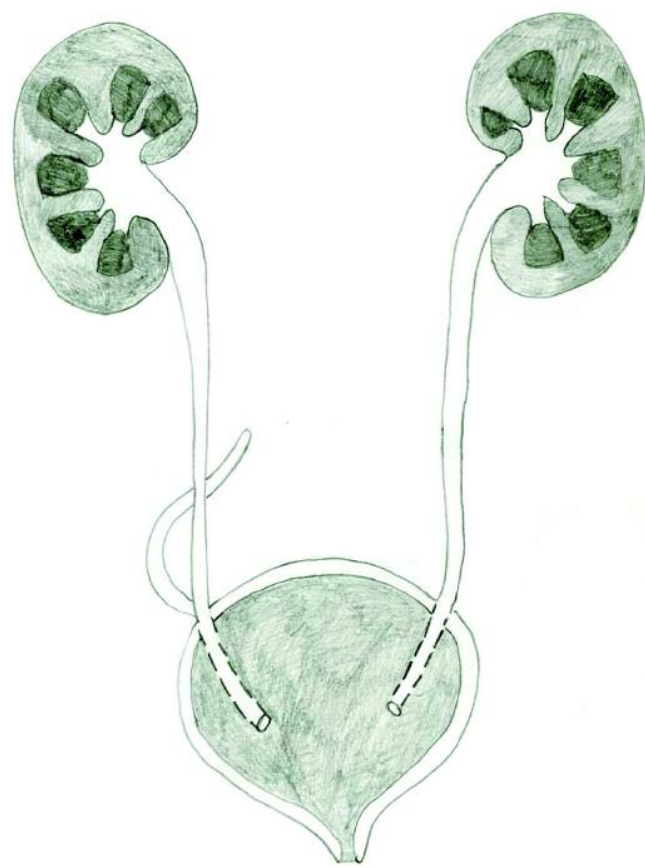

Figure 1. A schematic drawing of the blind-ending ureter

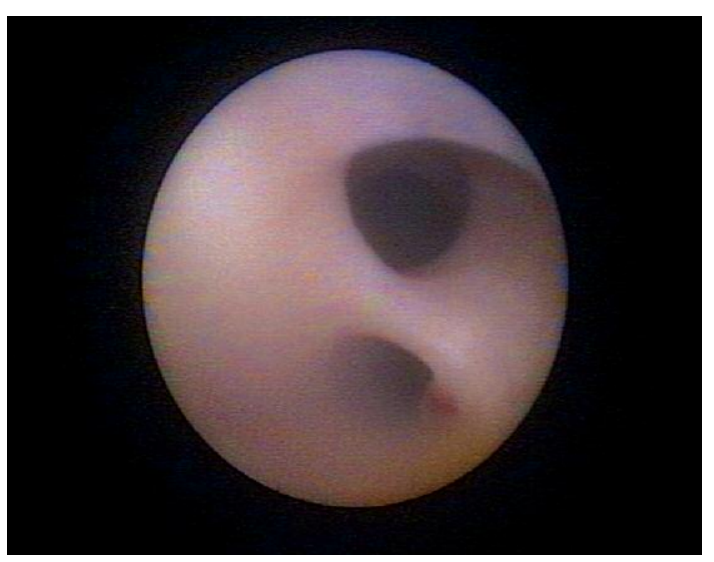

Figure 3. Normal and blind-ending ureter lumen orifice on diagnostic ureteroscopy

coureteric reflux or ureteral tumour [3-6]. Our patient did not have any symptoms or complications related to blind-ending bifid ureter. It was detected incidentally during the EU performed because of her complaints regarding the other ureter with stone.

Conventional approaches such as EU and retrograde ureterography in diagnosis of ureteral anomalies can be sufficient [2]. Our patient was easily diagnosed since she had a ureteroureteral reflux (yo-yo ureteric peristalsis) between the normal ureter and blind-ending branch detected in EU. Voiding cystouretrography may help diagnosis in patients with vesicoureteric reflux [5]. Multidetector computed tomography (CT) imaging urography $[5,7]$ and magnetic resonance urography can be

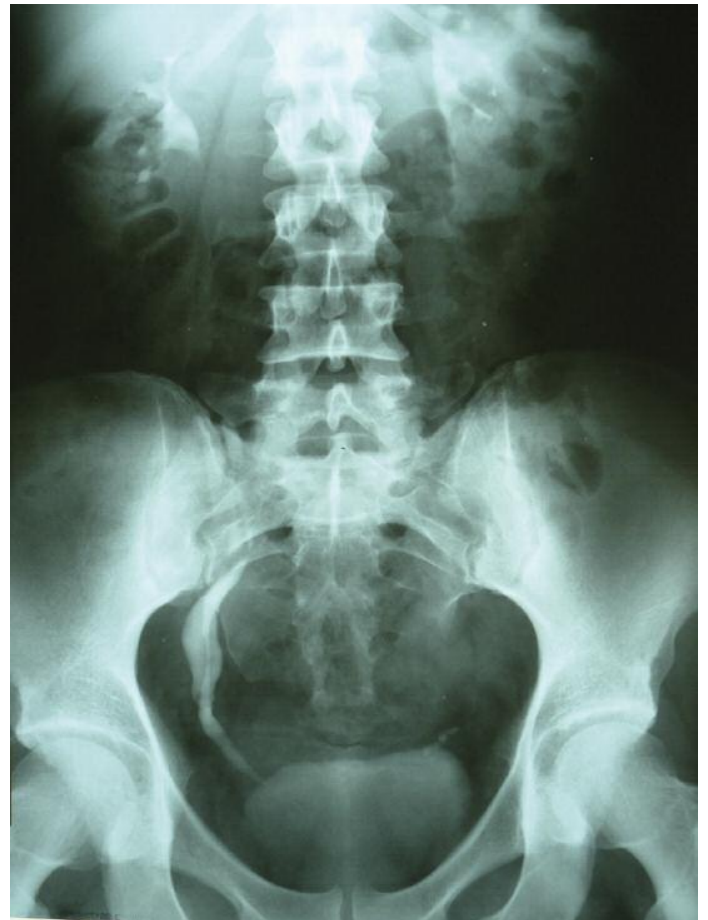

Figure 2. Right duplicated system with bifid blind-ending ureter on excretory urography

useful for diagnosis as alternative new advanced imaging methods [8]. However, these methods, being expensive, and multidetector CT having ionizing radiation, are disadvantageous. Another method for diagnosis of blind-ending bifid ureter may be ureteroscopy. This method is expensive and invasive but could be used in patients with planned surgery or in the presence of haematuria for the confirmation of diagnosis and evaluation of ureter lumen. We applied ureteroscopy in order to exclude other ureteral pathologies, and confirm the diagnosis. We recommend that the use of ureteroscopy is beneficial for such patients.

Treatment of symptomatic patients must be planned according to the complication. In our patient, as there was no complication following the treatment of the stone in the normal ureter, no surgery was performed on the ureter with the anomaly and the patient was placed in follow-up.

In conclusion, blind-ending bifid ureter is a rare entity, and unexpected complications during the surgery can be prevented if its probability is kept in mind, and it is visualized by diagnostic imaging methods and DU.

\section{Acknowledgments}

We thank Rukiye Dilli for her schematic drawing of Figure 1.

\section{References}

1. Bauer S, Perlmutter A, Retik A. Anomalies of the upper urinary tract. In: Walsh P, Retik A, Stamey TA, et al. (eds.). Campbell's urology. 6th ed. Sandauers, Philadelphia 1992; 1357-442. 
2. Choi JY, Kim SH, Kim SH. Double-blind ureteral duplication: report of two cases. Eur Radiol 2002; 12 Suppl 3: S136-9.

3. Halim HA, Al-Awadi KA, Kehinde EO, Mahmoud AH. Blindending ureteral duplication with calculi. Ann Saudi Med 2005; 25: 346-8.

4. Salakos C, Tyritzis SI, Papanastasiou D, Geropoulou E, Constantinides CA. Double-blind ureteral duplication: a rare urologic anomaly. Urology 2009; 73: 210.e1-2.

5. Rathi V. A blind-ending ureter with infection due to vesicoureteric reflux with associated renal agenesis: a rare cause of pain abdomen. Urol Ann 2011; 3: 100-2.

6. Kawamura H, Sasaki N. Transitional cell carcinoma in the blind-ending branch of the bifid ureter. Br J Urol 1998; 82: 307-8.

7. Chang E, Santillan C, O'Boyle MK. Blind-ending branch of a bifid ureter: multidetector CT imaging findings. Br J Radiol 2011; 84: e38-40.

8. Stimac G, Sucic M, Brigic I, Trnski D. Rare case of ectopic duplicated megaureter with dysplastic upper kidney moiety opening into ipsilateral ejaculatory duct. Urology 2006; 68: 672.e1-3. 